\title{
The Governance of the Healthcare System in Japan Under Aging Society
}

\author{
Lu Wang \\ Peking Union Medical College Hospital, Chinese Academy of Medical Sciences Peking Union \\ Medical College, Beijing, 100730, China
}

Graduate School of Interdisciplinary Information Studies, University of Tokyo, Japan

wanglug30@163.com

Keywords: Aging, healthcare system, public policy, UHC, long-term care.

\begin{abstract}
Health care system, a key component of social security system, concerns the vital interest of every individual life. Due to differences in the social system, economic development level and cultural background, countries vary in their choices of health care systems. However, when it comes to the issue of aging society, the models of health care system tend to converge to a more caring but less burden one. People nowadays, suffer a lot because of aging, and by an in-depth study on Japanese healthcare system under such background, this research is supposed to figure out a preliminary healthcare system that not only bring less burden for the government, but also benefits the public as much as possible without worsening the aging tendency.
\end{abstract}

\section{Introduction}

The aging problem has never failed to fascinate the whole world in the contemporary society, especially in countries like America, Japan, and China. Japan as the most rapidly aging country in the world has one of the world's comparatively largest elderly populations and to cope up with that, Japan has succeeded in developing a social security system that costs half as much and often achieves better medical outcomes than its American counterpart. However, as such system is highly counting on fiscal support, the biggest problem in health care system is that both the financing mechanism and the care-delivery system are extremely fragile. Except for this demerit, Japan symbolize the development period of speedy and high aging society of the Asia and is surely a model for all aging countries in Asia and it must be meaningful to research on its health system and find its advantages as well as shortcomings, thus trying to find tentative solutions.

\section{Defining and Measuring Old}

Different countries have different definition of the old age, even in the same country there could be various dimensions or standards in understanding aging. People usually classified according to their birth ages which means their age since they were born. In western countries, the old people are those aged older than 65, while in recent China 60 is the classification standard. Due to the aging tendency, WHO has already provided a new standard to define aging, that is, people from 60 to 74 are the young-old, those who older than 75 are the real old group of these days. There are also numerous other kinds of classification of the old, a popular one divided those older than 75 into two groups: those from 75 to 84 are the middle-old, and those who older than 85 are the oldest-old.

Other classification standard like physical age by the development of body apparatus, mental age by one's psychological level of maturity, and social age by one's social status. Different from the birth age, all of these kinds of age could be improved by exercises or personal efforts. 


\section{The Aging Situation in Japan}

The following data was taken from OECD statistic website which shows the percentage of the population over 65 that is on the upper part of the chart and the population over 80 on the lower part. As per Japan, it is apparent that it is the most rapid aging country all over the world.

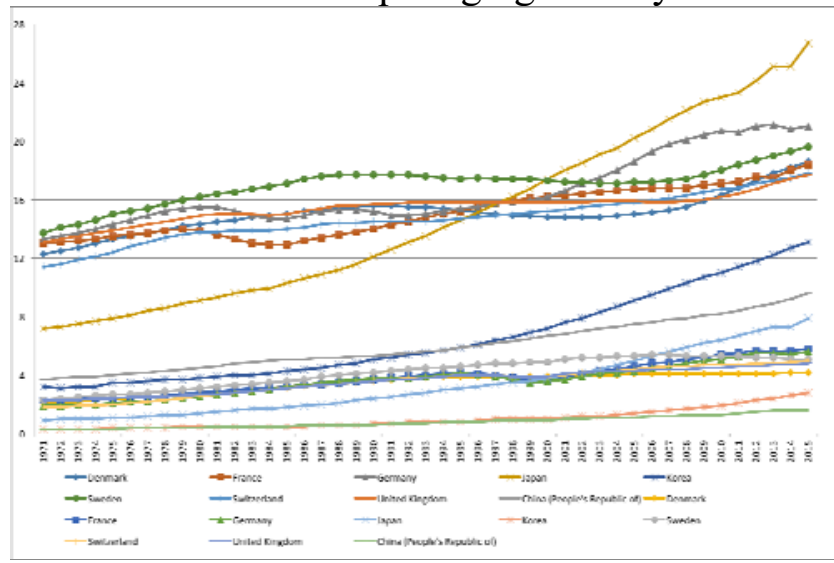

Fig 1. Percentage of the population over 65 and over 80 .

Besides such objective evidence that could be seen in numerous research before, a series of survey_ "Asian student survey" done among the youth in Asian in 2013 by professor Sonoda Shigeto from University of Tokyo could also demonstrate the seriousness of aging in Japan.

According to a question cited from the survey as "whether they think "the aging of society" is a threat to their country", I use SPSS to analysis the output which is showed as the follows. If the students believe that the aging issue in their country is pretty serious, they would choose 1 as the value of the answer, 0 would be right the other way around. Therefore, the closer to 1 the value, the more likely they regard the "aging society" as more threatening. As we could see, except Vietnam, Thailand, and Philippines, all of the other countries' youth consider the issue more or less threats to their countries. Japanese younger generation also suffered a lot due to aging situation, ranking only next to Singapore. Therefore, aging issue is extremely serious both subjectively and objectively.

2013 outcome of Q10-12: Country Code (HK included in China) * Which, if any, of the following issues do you think are threats to your country? (12) The aging of society (growing relative number of senior citizens) Cross tabulation

Table 1. SPSS analysis of the question "whether they think "the aging of society"

\begin{tabular}{|c|c|c|c|c|c|}
\hline & & & & & \\
\hline & & & 0 & 1 & Total \\
\hline & & Count & 129 & 605 & 734 \\
\hline & Korea & $\%$ within Country Code & $17.6 \%$ & $82.4 \%$ & $100.0 \%$ \\
\hline & & Count & 402 & 638 & 1040 \\
\hline & China & $\%$ within Country Code & $38.7 \%$ & $61.3 \%$ & $100.0 \%$ \\
\hline Country Code & Vietnam & $\begin{array}{c}\text { Count } \\
\% \text { within Country Code }\end{array}$ & $\begin{array}{c}440 \\
83.2 \%\end{array}$ & $\begin{array}{c}89 \\
16.8 \%\end{array}$ & $\begin{array}{c}529 \\
100.0 \%\end{array}$ \\
\hline (HK included in & Thoilond & Count & 320 & 105 & 425 \\
\hline China) & 17lananu & $\%$ within Country Code (HK included in China) & $75.3 \%$ & $24.7 \%$ & $100.0 \%$ \\
\hline & Philippines & $\begin{array}{c}\text { Count } \\
\text { o within } \text { Country }\end{array}$ & $\begin{array}{c}362 \\
898 \%\end{array}$ & $\begin{array}{c}41 \\
102 \%\end{array}$ & $\begin{array}{c}403 \\
1000 \%\end{array}$ \\
\hline & & Count & 29 & 292 & 321 \\
\hline & Singapore & $\%$ within Country Code & $9.0 \%$ & $91.0 \%$ & $100.0 \%$ \\
\hline & Jonot & Count & 62 & 400 & 462 \\
\hline & Japan & $\%$ within Country Code & $13.4 \%$ & $86.6 \%$ & $100.0 \%$ \\
\hline & Taiver & Count & 62 & 336 & 398 \\
\hline & Talwan & $\%$ within Country Code & $15.6 \%$ & $84.4 \%$ & $100.0 \%$ \\
\hline & & Count & 1806 & 2506 & 4312 \\
\hline
\end{tabular}


Japan has already succeeded in developing a social security system that costs half as much and often achieves better medical outcomes than its American counterpart. Not only could the elderly in Japan pay less for medical and the other treatments, but also the younger generations have various choices of social insurance for both their parents and themselves for the sake of aging issue. But things are still not perfect enough here. Although Japan enjoys the most developed medical system after the "ten-year gold plan", the biggest burden of such health system these days has been transferred to the funding system and fiscal policy for the sake of reducing the public medical share.

\section{Healthcare System in Japan}

Based on the existing studies on Japanese healthcare system in the age of aging society, I find that Japan has tried to not only cover public medical and health needs as much as possible, but also deal with the healthcare system in a quite low-cost way. According to the development of public insurance scheme in Japan in history, things changed gradually but steadily. In 1927, the government raised "employees' health insurance"; In 1938, changed to "community-based health insurance"; while in 1961, the scheme became "mandatory to join community-based health insurance for those who are not covered by employees' health insurance". When we look at these as a whole, we could find that public insurance, as an important part of healthcare system, tend to become more caring and more widely covered.

But these days, faced with the great burden on fiscal and economic, the government could no longer support the enormous expenditure on the health system and the concept UHC comes to the public which calls for sustainable development in the social health field. UHC which means universal health coverage, according to WHO is to ensure that all people obtain the health services they need without suffering financial hardship when paying for them.

Since it's quite a complicated issue when taking demography and the model social welfare which, as we all know, more spending may require a tax increase, thus, in turn, increase the public burden which might cause less sense of security in the end. But the investment on health haven't see any decrease. According to WHO, the chart below shows the index "government and private expenditure on health". Compared with Japan's $20 \%$ height of private expenditure Japan always enjoy a high level of government expenditure on health, thus the government assume the most responsibility for healthy expenses which means that the elderly people could enjoy a high level of public healthcare while the fiscal suffering a lot.

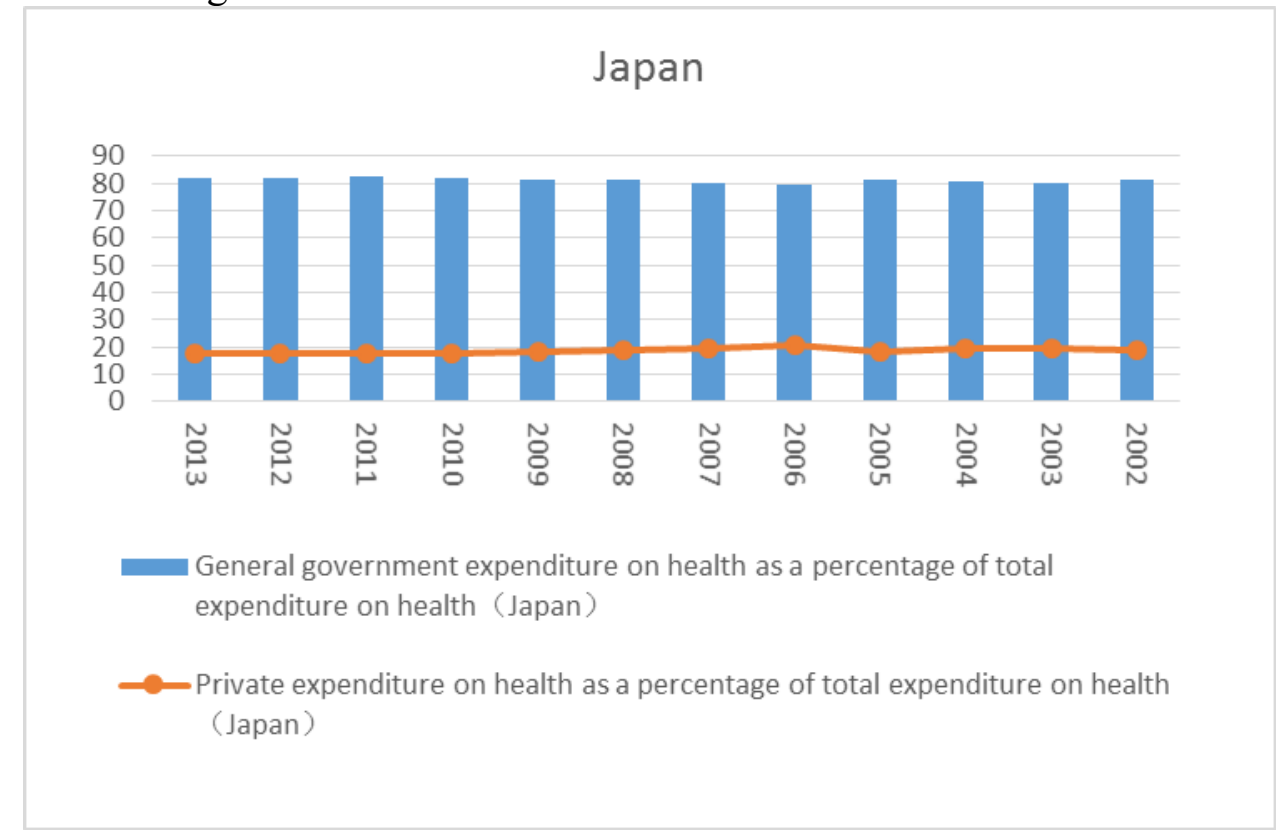

Fig 2. Government and private expenditure on health in Japan

According to "Annual Health, Labor and Welfare Report 2015", the greatest flaw in the governance of the healthcare funding system in Japan is that the provision of national health 
insurance, which is positioned as a last resort for medical care security, is fragmented into 1,717 municipalities, which provide the insurance. Also, medical expenditure constitutes another main part of government's expenditure. Recently, due to aging and innovation of new technologies, such expenditure is increasing. Since insurance premiums and tax funding are both limited because of the declining of working aged population, the budget of health care is faced with great pressure so far.

\section{Tentative Suggestions}

As what has been discussed, the government has already release series of policies to tackle such existing problems in healthcare system. For example, to cope with the lack of labor force, the government in Japan is encouraging Japan's seniors to remain in the workforce. The elderly people are not forced to retire before 65 and are capable and allowed to do whatever they want within their ability. What's more, Japanese government also try to make home a medical place. However, such method turned out to be less efficient till now, my general suggestions on such issue are as follows:

\subsection{Stick to UHC}

According to WHO World Health Report on aging and health in 2010, there are generally three dimensions to consider when moving towards universal coverage. First of all, direct cost which means the proportions of cost covered should be reduced. Secondly, the population that the healthcare system is covered is supposed to be more extended. Further, more the services should be included.

In order to harmonize the limited expenditure with the goal of UHC, the government is to increase the budget (like the insurance premium or patients' out of pocket part) on medical area so as to developing advancing medical technology that benefit the whole nations in the long run. Also, the limitation on the insurance coverage might be helpful at present. Furthermore, the regulation on medical facilities and try to find a balanced pricing mechanism are also of great significance.

\subsection{A more Caring Society}

According to Susan E. Matthews, America has been also faced with aging problem. In her essay, she made the point that "By 2030, one in five Americans will be over age 65, and the healthcare system is just beginning to feel the burden." On account of that, she calls for a more caring but less burden health care system.

In order to develop a more caring system, there are 3 steps.

(1). Improve efficiency of healthcare system by improving effective network of care.

Japanese government should carry out effective governance strengthening at global, national and community levels. Cooperation among these various levels is highly recommended, for health policy shouldn't be designed separately, more collaboration makes better policy.

(2). Build up an integrated home-based healthcare system

Since home-based nursing is the most suitable style based on Japanese aging situation, strengthened collaboration between home medical care and nursing system would improve the whole community care to a large distance.

(3). Promotion of long-term care.

More caring is not necessarily mean more expenditure. Japan has suffered from serious healthcare problem because of aging back in early 2000s, just as what Etsuji Okamoto mention in his essay "the Japanese health system has not been sufficiently prepared to respond the needs of the growing elderly population." Also, healthier elderly people would mean less medical and insurance expenditure overall. Only when the whole system exerts more importance on preventive and long-term care, rather than merely focus on curing and rehabilitation, will the government be well prepared for the growing elderly population.

\section{References}

[1]. Tsuno, N., \& Homma, A. (2009). Ageing in Asia-the Japan experience. Ageing International, 34(1-2), 1-14. 
[2]. Freeman, S., Kurosawa, H., Ebihara, S., \& Kohzuki, M. (2010). Caregiving burden for the oldest old: A population-based study of centenarian caregivers in Northern Japan. Archives of gerontology and geriatrics, 50(3), 282-291.

[3]. OECD (2015), Health at a Glance 2015: OECD Indicators, OECD Publishing, Paris. http://dx.doi.org/10.1787/health_glance-2015-en

[4]. WHO (2010), World Health Report on aging and health. www.who.int

[5]. Etsuji Okamoto (2014), Current Issued and future Challenges facing Japan's Health Care System

[6]. Susan E. Matthews (2013), How the Aging Population Is Changing the Healthcare System

[7]. Yukihiro Matsuyama (2014), Aging and the governance of the Healthcare system in Japan

[8]. Blizin, Jerry (2010), Health care war, cries of socialism: The Medicare was born. 